Article

\title{
Recycled and Virgin HDPEs as Bleed Inhibitors and Their Rheological Influences on Lubricating Greases Thickened with PP and $\mathrm{mPP}$
}

\author{
Ravi Dixena ${ }^{1, *}$, Eltepu Sayanna ${ }^{1}$ and Rajendra Badoni ${ }^{2}$ \\ 1 Indian Oil Corporation Limited, R\&D Centre, Sector-13, Faridabad PIN-121007, Haryana, India; \\ E-Mail: sayannae@indianoil.in \\ 2 College of Engineering Studies, University of Petroleum and Energy Studies, Dehradun \\ PIN-248007, India; E-Mail: rpbadoni@ddn.upes.ac.in \\ * Author to whom correspondence should be addressed; E-Mail: dixenark@indianoil.in; \\ Tel.: +91-997-162-6161.
}

Received: 7 August 2014; in revised form: 18 September 2014 / Accepted: 24 September 2014 / Published: 18 December 2014

\begin{abstract}
Polypropylene (PP) thickened lubricating grease exhibits high oil bleed tendency at low temperatures, which makes it a promising candidate for low temperature applications. At elevated temperatures, PP thickened lubricating grease exhibits excessive oil bleeding, which limits its use at high temperatures. Excessive oil bleed adversely affects the lubricating performance of the PP thickened grease. The present work is focused on the study of the oil bleed tendency of PP and Maleated Polypropylene (mPP) thickened greases at various temperatures by incorporating virgin and recycled high density polyethylene (HDPE) into the thickener system. Grease containing various percentages of PP and mPP thickeners were prepared and modified with different percentages of virgin and recycled HDPE. Polymers were characterized through differential scanning calorimetry (DSC) techniques. The oil bleed performance of these greases was evaluated by the conical sieve method (ASTM D 6184) at various temperatures. Storage $\left(\mathrm{G}^{\prime}\right)$ and loss modulus $\left(\mathrm{G}^{\prime \prime}\right)$ of greases was determined by rheometry at $25{ }^{\circ} \mathrm{C}$. Incorporation of HDPE and recycled HDPE in PP thickened grease decreased oil bleeding compared to the base grease.
\end{abstract}

Keywords: lubricating grease; rheology; polypropylene; high density polyethylene; oil separation; heat stability 


\section{Introduction}

Lubricating grease is a three component system, i.e., thickener, base oil and performance additives, used predominantly for the lubrication of bearing elements and low speed gear systems [1]. Grease consistency is an important measure for the selection of a grease for specific applications [2]. Proportion and type of base oil and thickener in lubricating greases influences a number of properties including consistency and rheology $[3,4]$. The lubricating grease serves as a reservoir for lubricating oil and an optimum release of lubricating oil during operation is desirable for good lubrication performance. Oil release from lubricating greases is induced by mechanical forces and temperature. Insufficient oil release or excessive loss of oil from lubricating grease causes lubricant starvation and may lead to bearing failure $[5,6]$. Oil bleeding rate directly affects the useful service life and performance of the bearing; thus, it is apparent that oil bleed characteristics of lubricating grease have a role in performance assessment of lubricating greases. Hence, due significance has been given by various researchers to study and improve oil bleed characteristics of various types of lubricating greases [4,7-9]. There are several research papers available focusing on other aspects of polymer thickened greases [10-15], but oil bleed tendency at high temperatures and methods of improvement has hardly been studied in detail [16]. Polymers are grafted with some functional groups to further improve the existing properties or to induce additional properties in the field of concern [17-19] such as flow, oil bleed, etc. Recycled polymers are cheaper source of material and are easily available with a wide range of grades from single recycled to non-reusable waste. Attempts were made by researchers in the recent past to study the application potential of different types of recycled polymers in lubricating greases $[12,15]$. This research work aims to study the effect of recycled and virgin HDPE on bleeding tendency of PP and $\mathrm{mPP}$ thickened greases over a wide temperature range and any change in rheological properties therein.

\section{Experimental Section}

\subsection{Materials}

A mixture of group I and group II paraffinic mineral lubricating oils (Kinematic Viscosity $160 \mathrm{cSt}$ at $40{ }^{\circ} \mathrm{C}$ ) supplied by Indian Oil Corporation Ltd. (Faridabad, India) was used to prepare lubricating grease samples. Polypropylene and Maleated Polypropylene, supplied by Pluss Polymers Pvt. Ltd. (New Delhi, India) were used as thickeners. Raffia grade virgin high density polyethylene from Indian Oil Corporation Ltd. and recycled cream colored high density polyethylene from plastic scrap available with the same trade name was used as an additive, which was supplied by a local supplier. Melting temperature $\left(T_{\mathrm{m}}\right)$, fusion enthalpy $\left(\Delta H_{\mathrm{f}}\right)$ and other physical properties of polymers are given in Table 1.

\subsection{Grease Manufacturing}

Gel like dispersion of polymers was prepared using Sotelem reactor model RMP 5005 through batch process under nitrogen atmosphere. The contents were heated up to $200-210{ }^{\circ} \mathrm{C}$ with constant stirring at $150 \mathrm{rpm}$. After $1 \mathrm{~h}$ the material was poured into 20 liter steel container and quenched with dry ice to 70-90 ${ }^{\circ} \mathrm{C}$. The material was then milled in a Colloid Mill (Model JC 100) to obtain grease. The processing and milling parameters for all the samples were kept identical. With the same percentage 
composition, both PP and mPP have different thickening tendencies. Hence, thickener proportion was adjusted to obtain target consistency (worked cone penetration of 270 to 300 ). $18 \% \mathrm{PP}$ and $15.5 \% \mathrm{mPP}$ gave desired consistency. Twenty-six greases with different PP, mPP and HDPE (virgin and recycled) concentrations were studied; detailed compositions are given in Table 2.

Table 1. Weight average molecular weight $M_{\mathrm{w}}$, number average molecular weight $M_{\mathrm{n}}$, polydispersity $\left(M_{\mathrm{w}} / M_{\mathrm{n}}\right)$, melting temperature $\left(T_{\mathrm{m}}\right)$ and fusion enthalpy $\left(\Delta H_{\mathrm{f}}\right)$ of polymers. * Supplied by manufacturer.

\begin{tabular}{cccccccc}
\hline Sample & MFI * (g/10 min) & Density & $\boldsymbol{M}_{\mathbf{w}}$ & $\boldsymbol{M}_{\mathbf{n}}$ & $\boldsymbol{M}_{\mathbf{w}} / \boldsymbol{M}_{\mathbf{n}}$ & $\boldsymbol{T}_{\mathbf{m}}$ & $\boldsymbol{\Delta} \boldsymbol{H}_{\mathbf{f}}$ \\
\hline Polypropylene (PP) & 1700 & n.a. & $1.20 \times 10^{5}$ & $3.8 \times 10^{4}$ & 3.2 & 161.5 & 102 \\
\hline $\begin{array}{c}\text { Maleated } \\
\text { Polypropylene }\end{array}$ & 120 & n.a. & $1.42 \times 10^{5}$ & $5.1 \times 10^{4}$ & 2.8 & 160 & 109 \\
\hline $\begin{array}{c}\text { (mPP) } \\
\text { HDPE }\end{array}$ & 0.9 & 0.952 & $5.73 \times 10^{5}$ & $4.6 \times 10^{4}$ & 12 & 132 & 237 \\
\hline $\begin{array}{c}\text { Recycled HDPE } \\
\text { (rHDPE) }\end{array}$ & 1.55 & n.a. & $3.95 \times 10^{5}$ & $3.3 \times 10^{4}$ & 11.9 & 131.5 & 219 \\
\hline
\end{tabular}

Table 2. Percentage composition of polymers in greases.

\begin{tabular}{cccccccc}
\hline Sample & $\begin{array}{c}\text { \% of } \\
\text { PP }\end{array}$ & $\begin{array}{c}\text { \% of } \\
\text { HDPE }\end{array}$ & $\begin{array}{c}\text { \% of } \\
\text { rHDPE }\end{array}$ & Sample & $\begin{array}{c}\text { \% of } \\
\text { mPP }\end{array}$ & $\begin{array}{c}\text { \% of } \\
\text { HDPE }\end{array}$ & $\begin{array}{c}\text { \% of } \\
\text { rHDPE }\end{array}$ \\
\hline PP18 & 18 & nil & nil & mpp15.5 & 15.5 & nil & nil \\
PP17.5 & 17.5 & nil & nil & mPP15 & 15 & nil & nil \\
PP17 & 17 & nil & nil & mPP14.5 & 14.5 & nil & nil \\
PP16 & 16 & nil & nil & mPP13.5 & 13.5 & nil & nil \\
PP14 & 14 & nil & nil & mPP11.5 & 11.5 & nil & nil \\
PP+HDPE0.5 & 17.5 & 0.5 & nil & mPP+HDPE0.5 & 15 & 0.5 & nil \\
PP+HDPE1 & 17 & 1 & nil & mPP+HDPE1 & 14.5 & 1 & nil \\
PP+HDPE2 & 16 & 2 & nil & mPP+HDPE2 & 13.5 & 2 & nil \\
PP+HDPE4 & 14 & 4 & nil & mPP+HDPE4 & 11.5 & 4 & nil \\
PP+rHDPE0.5 & 17.5 & nil & 0.5 & mPP+rHDPE0.5 & 15 & nil & 0.5 \\
PP+rHDPE1 & 17 & nil & 1 & mPP+rHDPE1 & 14.5 & nil & 1 \\
PP+rHDPE2 & 16 & nil & 2 & mPP+rHDPE2 & 13.5 & nil & 2 \\
PP+rHDPE4 & 14 & nil & 4 & mPP+rHDPE4 & 11.5 & nil & 4 \\
\hline
\end{tabular}

\subsection{Gel Permeation Chromatography}

High temperature gel permeation chromatography (HT-GPC) analysis of all the polymers was carried out on PLGPC 220 HTGPC equipment fitted with a Refractive Index (RI) measurement facility. The oven compartment is fitted with an injection valve, GPC columns and Differential Refractive Index (DRI) detector. The weight-average molecular weight, $M_{\mathrm{w}}$, number-average molecular weight, $M_{\mathrm{n}}$, and poly-dispersity, $M_{\mathrm{w}} / M_{\mathrm{n}}$, values are listed in Table 1. 


\subsection{Differential Scanning Calorimetry}

Differential scanning calorimetry (DSC) was performed with a Mettler Toledo Instrument. Each test sample was weighed to about $10 \pm 2 \mathrm{mg}$, sealed in standard aluminum pans was subjected to heating cycles from 25 to $200{ }^{\circ} \mathrm{C}, 200$ to $25{ }^{\circ} \mathrm{C}, 25$ to $200{ }^{\circ} \mathrm{C}$ at a heating rate of $20{ }^{\circ} \mathrm{C} / \mathrm{min}$ in first heating cycle and $10{ }^{\circ} \mathrm{C} / \mathrm{min}$ in second heating cycle; with nitrogen flow rate of $50 \mathrm{~mL} / \mathrm{min}$. The heat flow curve of the second heating cycle was taken for study.

\subsection{Heat Stability Test}

The ASTM D-6184 test method was followed to study the heat stability property in terms of oil bleed tendency for all the grease samples at temperatures $60,80,100$, and $120^{\circ} \mathrm{C}$. An oven capable of maintaining up to $150 \pm 0.5{ }^{\circ} \mathrm{C}$ was used for study. The test was conducted in duplicate for $30 \mathrm{~h}$ for study in each temperature and the average of two results was reported.

\subsection{Cone Penetration Test}

To determine the unworked and worked (60 double stroke) penetration of the lubricating grease, cone penetration test was performed using Seta penetrometer model 17500-0 for all the samples as per the ASTM D-1403 (half scale geometry) and values obtained were converted into the full scale cone penetration values applying the factor as per ASTM D-217.

\subsection{Rheological Studies}

Rheological measurements were carried out with a controlled strain rheometer (Anton Paar Physica MCR 301). All samples having same thermal history (during grease manufacturing) were subjected to a strain sweep test at a frequency of $1 \mathrm{~Hz}$ to determine the linear viscoelastic region. SAOS (small amplitude oscillatory sweep) measurements were carried out inside the linear viscoelastic region using a $25 \mathrm{~mm}$, Plate-Plate geometry at $1 \mathrm{~mm}$ gap in a frequency range between $10^{-2}$ and $10^{2} \mathrm{rad} / \mathrm{s}$ at $25^{\circ} \mathrm{C}$.

\section{Results and Discussion}

\subsection{Differential Scanning Calorimetry}

A DSC measurement was carried out for all polymer samples and the thermograms of samples corresponding to the second heating cycle are displayed in Figure 1. Single endothermic peak appears at $132{ }^{\circ} \mathrm{C}$ and $131.5{ }^{\circ} \mathrm{C}$ for HDPE and recycled HDPE respectively, which can be attributed to their characteristic melting temperatures. The fusion endotherm of PP and $\mathrm{mPP}$ show the characteristic melting peak at $161.5^{\circ} \mathrm{C}$ and $160{ }^{\circ} \mathrm{C}$ respectively. The melting temperature and fusion enthalpy values for all the above polymers are reported in Table 1. 
Figure 1. Differential scanning calorimetry (DSC) heat flow curves of Polypropylene (PP), maleated Polypropylene (mPP), high density polyethylene (HDPE) and recycled HDPE (rHDPE).

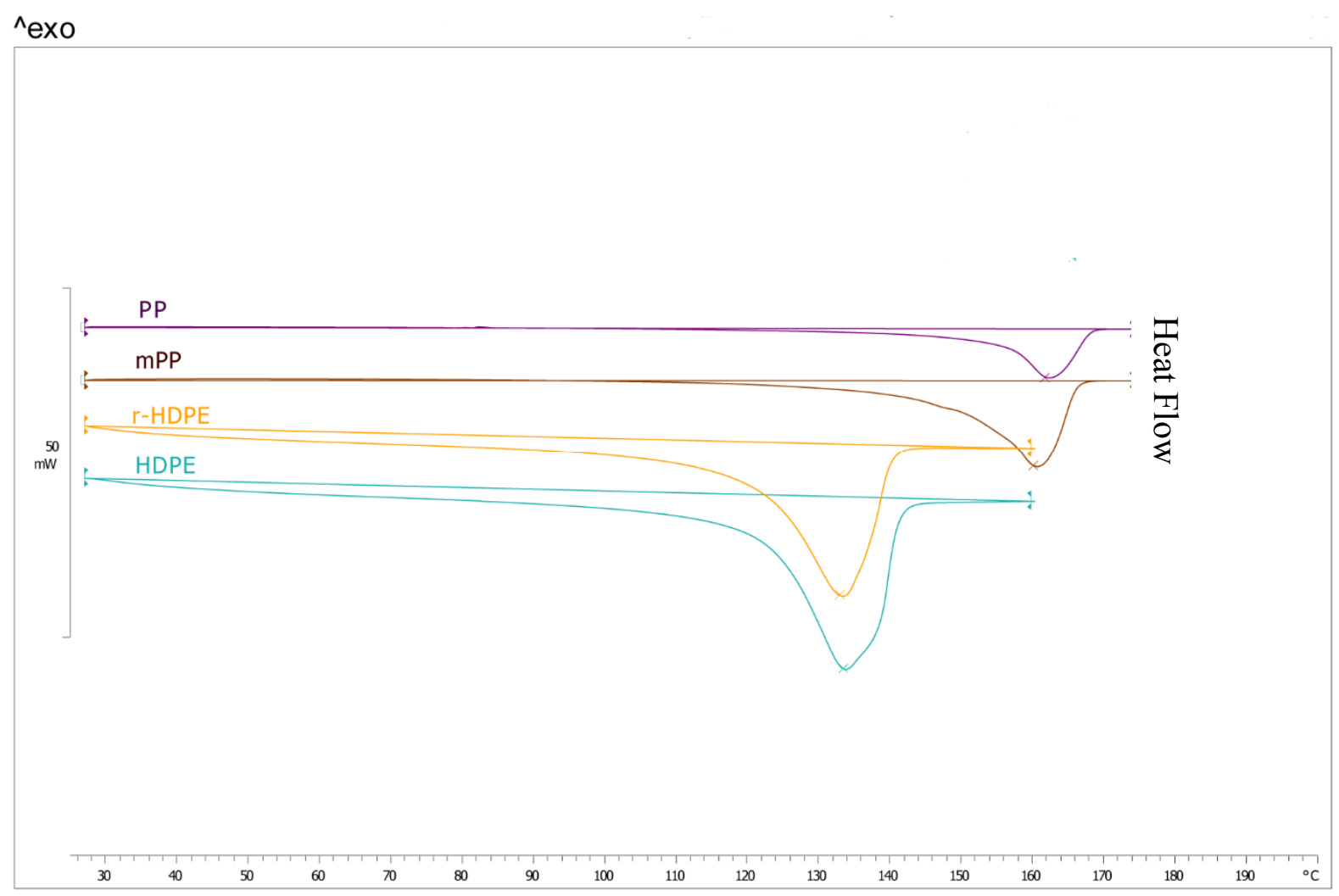

\subsection{Heat Stability}

The heat stability (oil bleed tendency) of greases PP, mPP and their compositions modified with HDPE and rHDPE were studied at temperatures $60,80,100 \& 120^{\circ} \mathrm{C}$ following ASTM D-6184 standard method. Figure 2 shows plots of heat stability versus temperature for all the samples studied. The trend is similar in all the plots, i.e., minimum at low temperature and maximum at high temperature, irrespective of thickener type. An increase in oil bleed tendency was observed with decrease in thickener content and vice versa in both the thickener types PP and $\mathrm{mPP}$ over entire temperature range studied (Figure 2a,d). A similar observation was reported by Cann, P. M. [20] with lithium hydroxystearate thickener. Figure $2 b, c$ represents the oil bleed performance of PP and $\mathrm{mPP}$ thickened greases modified with HDPE. An improvement in oil bleed performance was observed which increases with the HDPE content in thickener, there was a marginal improvement noticed with PP+HDPE0.5 and PP, i.e., with 0.5\% HDPE content. An improvement of more than $60 \%$ was observed with 4\% HDPE content, both with PP and $\mathrm{mPP}$ thickened greases. A gradual and consistent improvement in oil bleed performance was noticed above $0.5 \%$ HDPE content. The performance of recycled HDPE was quite similar to virgin HDPE's performance.

In general, the oil retention ability of PP grease is better than HDPE grease due to its well-formed microstructural network in oil medium, similar to a lithium lubricating grease, whereas HDPE remains coiled and dispersed with poor oil retention capacity [15]. As reported by J. E. Martin-Alfonso et al., HDPE acts as filler in lithium lubricating grease, thereby improving grease structure. However, it is 
speculated that the portion of HDPE soluble in base oil increases viscosity [21]. Hence, when grease was blended with PP an improvement in oil bleed performance was noticed due to influence on base oil viscosity. Oil bleed tendency of PP grease is highly temperature sensitive and abrupt increase of oil bleed with temperature is observed [22] (Figure 2). On the other hand a PP+HDPE blend was more stable than pure PP grease over a wide temperature range. This may be a result of increased oil retention capacity by HDPE due to uncoiling of chain with increasing temperature. (There are other physico-chemical properties like base oil and thickener interaction, base oil viscosity [20], which actuates the release of base oil from grease when the temperature is raised). Nevertheless, addition of HDPE (virgin and recycled) improves oil bleed tendency compared to pure PP and mPP grease, the oil bleed tendency at high temperature remains always higher than oil bleed tendency at low temperature due to the aforementioned counter phenomenon.

Figure 2. Oil bleed tendency in percentage ( $y$ axis) versus Temperature in ${ }^{\circ} \mathrm{C}$ ( $x$ axis), PP grease with varying thickener content (a), PP grease modified with HDPE (b), PP grease modified with recycled HDPE (c), mPP grease with varying thickener content (d), mPP modified with HDPE (e), mPP modified with rHDPE (f).
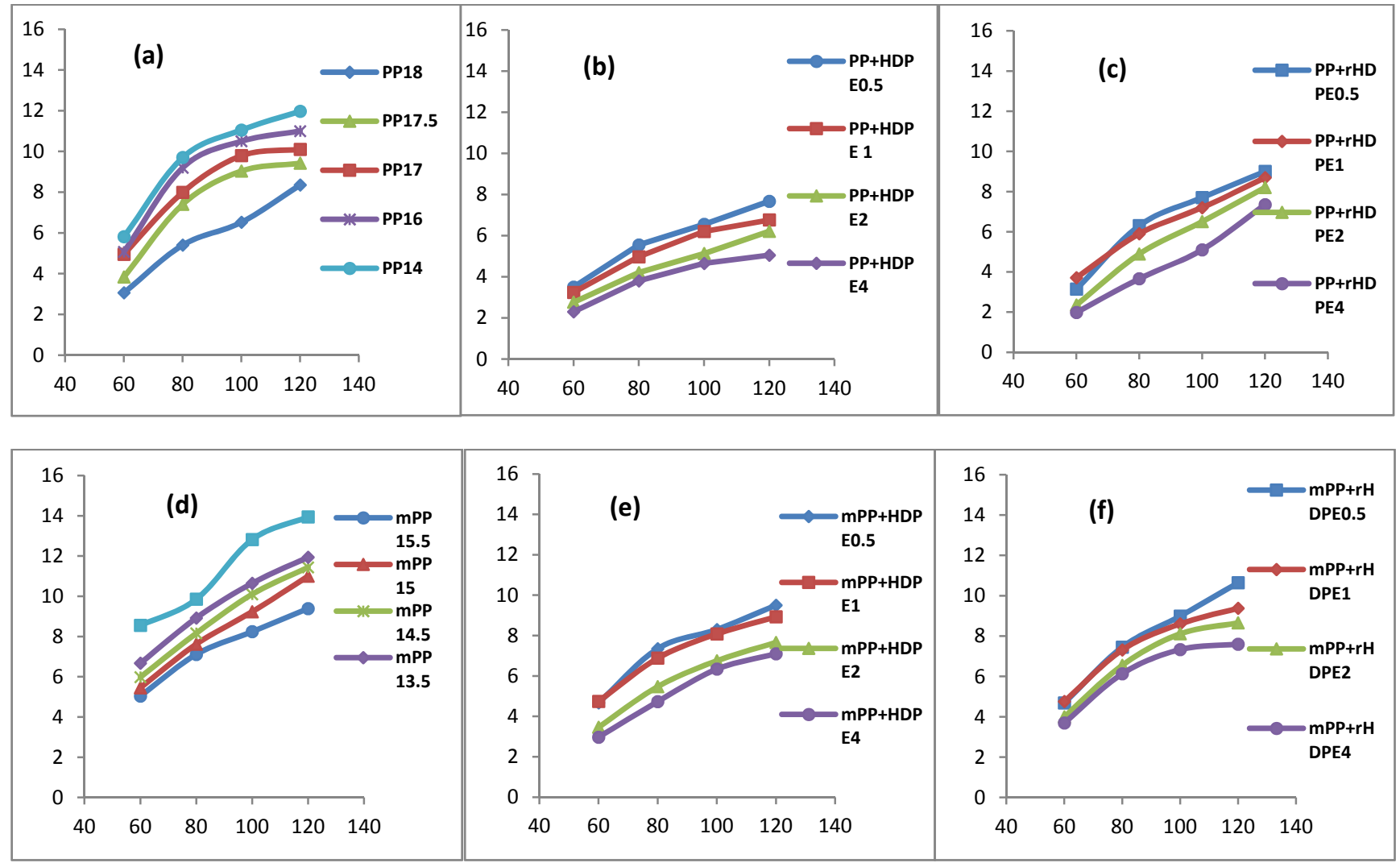

\subsection{Cone Penetration Test}

Unworked and worked cone penetration values of all the samples are shown in Table 3. The penetration values of samples increases with decreasing thickener content which is quite obvious. All the polymers have different thickening capacity with same thickener content; the order of thickening tendency is HDPE $>\mathrm{mPP}>$ PP. Both virgin and recycled HDPE show a higher thickening tendency than other polymers, therefore in replacing PP and mPP with HDPE (virgin and recycled), more than 2 percent 
shows low unworked and worked penetration values. The differences between unworked and worked penetration values of polymeric greases are highly dependent on milling conditions and processing parameters. Slight change of a parameter like milling time and temperature may result in significant change in unworked and worked penetration values. Therefore, care has been taken to keep the process and milling conditions identical.

Table 3. Unworked and worked cone penetration and $G_{\mathrm{N}}{ }^{0}$ values of grease samples.

\begin{tabular}{cccc|cccc}
\hline Sample & $\begin{array}{c}\text { Unworked } \\
\text { Penetration }\end{array}$ & $\begin{array}{c}\text { Worked } \\
\text { Penetration }\end{array}$ & $\boldsymbol{G}_{\mathbf{N}}^{\mathbf{0}}$ & Sample & $\begin{array}{c}\text { Unworked } \\
\text { Penetration }\end{array}$ & $\begin{array}{c}\text { Worked } \\
\text { Penetration }\end{array}$ & $\boldsymbol{G}_{\mathbf{N}}^{\mathbf{0}}$ \\
\hline PP18 & 217 & 269 & 86,700 & mpp15.5 & 231 & 287 & 81,300 \\
PP17.5 & 235 & 279 & 71,500 & mPP15 & 257 & 303 & 57,400 \\
PP17 & 259 & 291 & 56,300 & mPP14.5 & 265 & 311 & 56,100 \\
PP16 & 279 & 303 & 52,700 & mPP13.5 & 275 & 315 & 40,900 \\
PP14 & 293 & 337 & 17,266 & mPP11.5 & 315 & 345 & 15,700 \\
PP+HDPE0.5 & 217 & 271 & 78,833 & mPP+HDPE0.5 & 243 & 293 & 52,950 \\
PP+HDPE1 & 241 & 277 & 78,166 & mPP+HDPR1 & 253 & 289 & 59,620 \\
PP+HDPE2 & 237 & 275 & 87,920 & mPP+HDPE2 & 243 & 285 & 77,250 \\
PP+HDPE4 & 225 & 263 & 115,666 & mPP+HDPE4 & 211 & 269 & 122,000 \\
PP+rHDPE0.5 & 231 & 281 & 83,100 & mPP+rHDPE0.5 & 243 & 295 & 58,100 \\
PP+rHDPE1 & 235 & 279 & 81,300 & mPP+rHDPE1 & 243 & 291 & 58,725 \\
PP+rHDPE2 & 219 & 277 & 89,100 & mPP+rHDPE2 & 227 & 273 & 87,600 \\
PP+rHDPE4 & 207 & 253 & 124,000 & mPP+rHDPE4 & 227 & 267 & 97,300 \\
\hline
\end{tabular}

\subsection{Rheological Studies}

Figure 3 shows the viscoelastic response of PP and mPP grease with frequency as a function of thickener concentration and HDPE (virgin and recycled) concentration in the linear viscoelastic range. It was observed that the frequency dependence of all samples studied was similar to that found with other lubricating greases as reported in the past [15]. As is evident from Figure 3, the SAOS response of PP and mPP thickened greases are very similar. Moreover, the SAOS response as a function of thickener content is also similar and hence only PP thickened system will be quoted for further discussion. A high $\mathrm{G}^{\prime \prime}$ than $\mathrm{G}^{\prime}$ was reported for polypropylene (amorphous and recycled) thickener system with $\leq 9 \%$ thickener content in a previous study [23]. On the other hand, the present study shows a high storage modulus than the loss modulus for all the samples studied as a consequence of high thickener content $(\leq 18 \%$ for $\mathrm{PP}$ and $\leq 15.5 \%$ for $\mathrm{mPP}$ ) a more elastic in nature than viscous and hence, loss tangent values are below zero.

Figure $3 \mathrm{a}, \mathrm{g}$ shows variation of $\mathrm{G}^{\prime}$ and $\mathrm{G}^{\prime \prime}$ as a function of thickener concentration. The values of SAOS function decrease with a decrease in thickener concentration and the decrease in storage modulus is more prominent than loss modulus. A dominance of viscous response over elastic response was observed with a decrease in thickener concentration. Reduction in thickener content results in to less compact microstructural network with fewer entanglements between network fibers. As is evident from Figure $3 \mathrm{~b}, \mathrm{~h}$, a high tangent value from intermediate to high frequency range is similar to that reported in systems with highly entangled structural networks [24]. 
The plateau modulus $G_{\mathrm{N}}{ }^{0}$ (Table 3 ) is a characteristic parameter of the highly structured polymeric system, having interchain contact points, here it is estimated as,

$$
G_{\mathrm{N}}{ }^{0}=\left[\mathrm{G}^{\prime}\right] \tan \delta \rightarrow \min
$$

Although all the samples show a characteristic plateau region at intermediate to high frequencies (Figure 3) an increase in plateau modulus was observed with increase in PP/HDPE ratio. Moreover, the plateau region shifted to higher frequency range with increase in HDPE content. The grease with high HDPE content shows higher viscoelastic response than grease with low or no HDPE content in relation to the grease with similar overall thickener content. For polymers of the same molecular weight, the degree of branching is a crucial parameter to influence rheological properties of a given solvent. A linear polymer shows a more viscous response than branched polymer of the same molecular weight [21] and as expected, a relatively high modification on viscous response was observed than elastic response on partially replacing PP by HDPE. From the foregoing discussion, it can be anticipated that the more viscous structure (high $\mathrm{G}^{\prime \prime}$ ) would mean more oil bleed at high temperatures, whereas more elastic structures (high $\mathrm{G}^{\prime}$ ) would result in less oil bleed or compact structure.

Figure 3. Evolution of storage modulus $\left(\mathrm{G}^{\prime}\right)$ and loss modulus $\left(\mathrm{G}^{\prime \prime}\right)$ and loss tangent $(\tan \delta)$ with frequency for PP and mPP greases with different PP/mPP concentrations (a,b,g,h), PP and mPP modified with HDPE (c,d,i,j), PP and mPP modified rHDPE (e,f,k, $\mathbf{l})$.

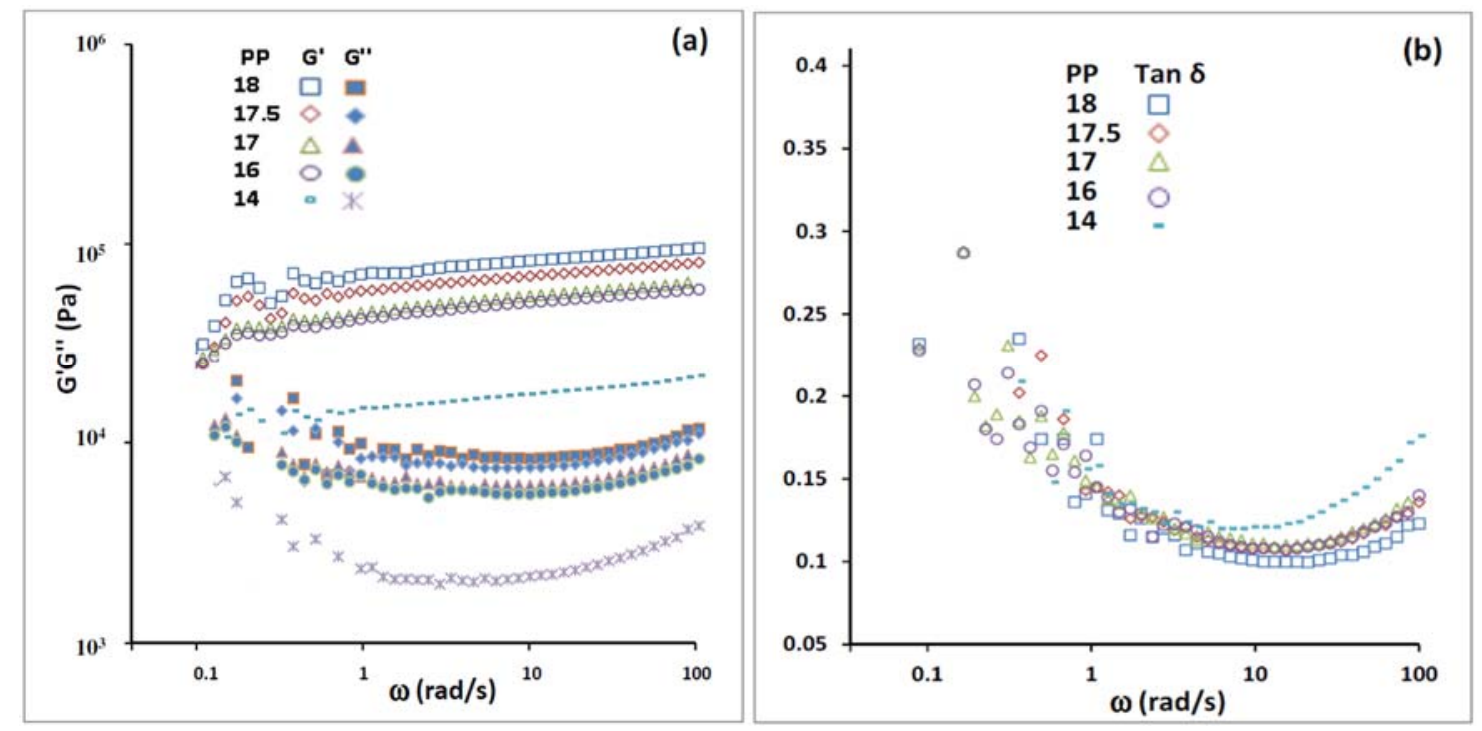


Figure 3. Cont.
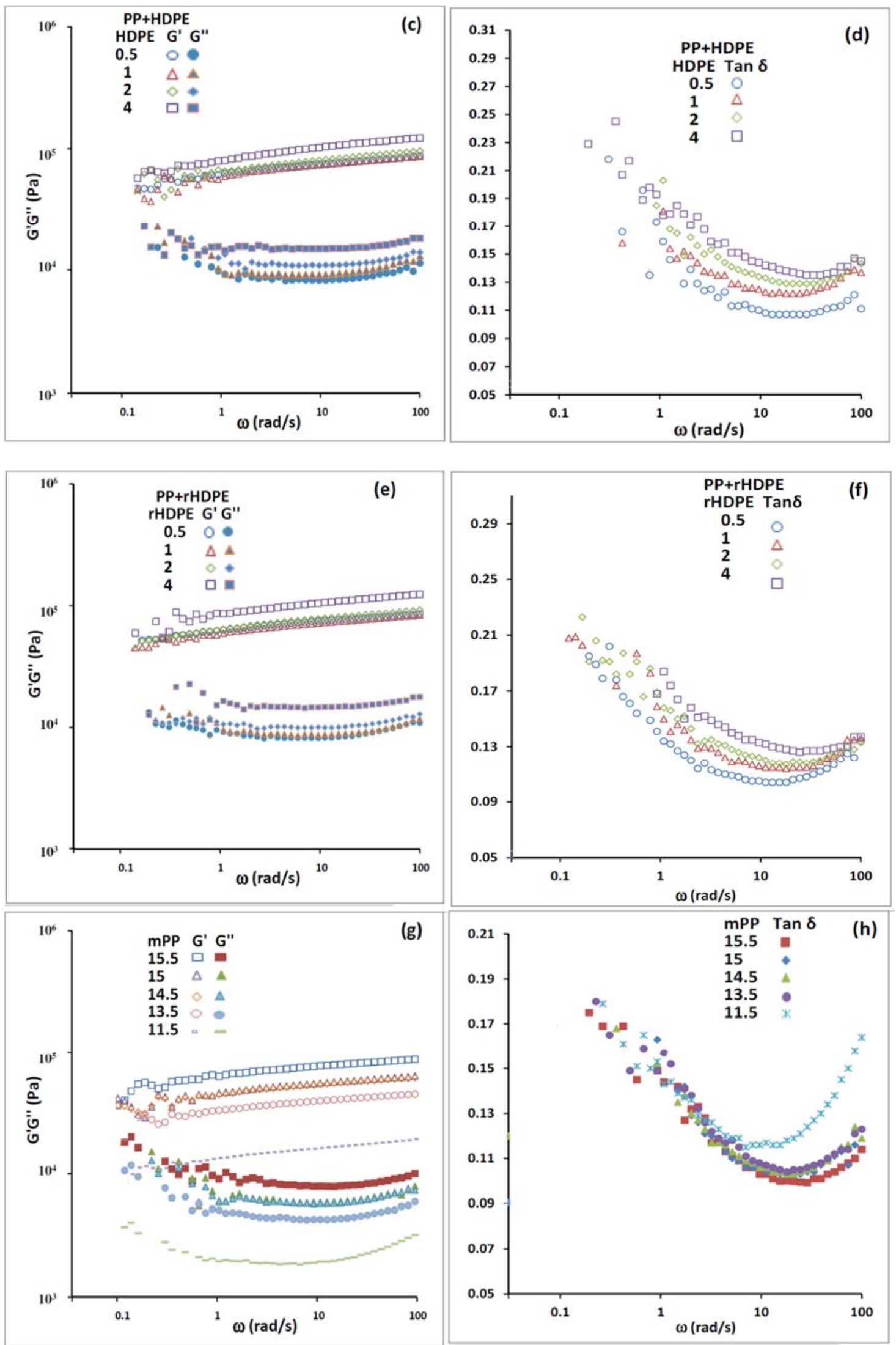
Figure 3. Cont.

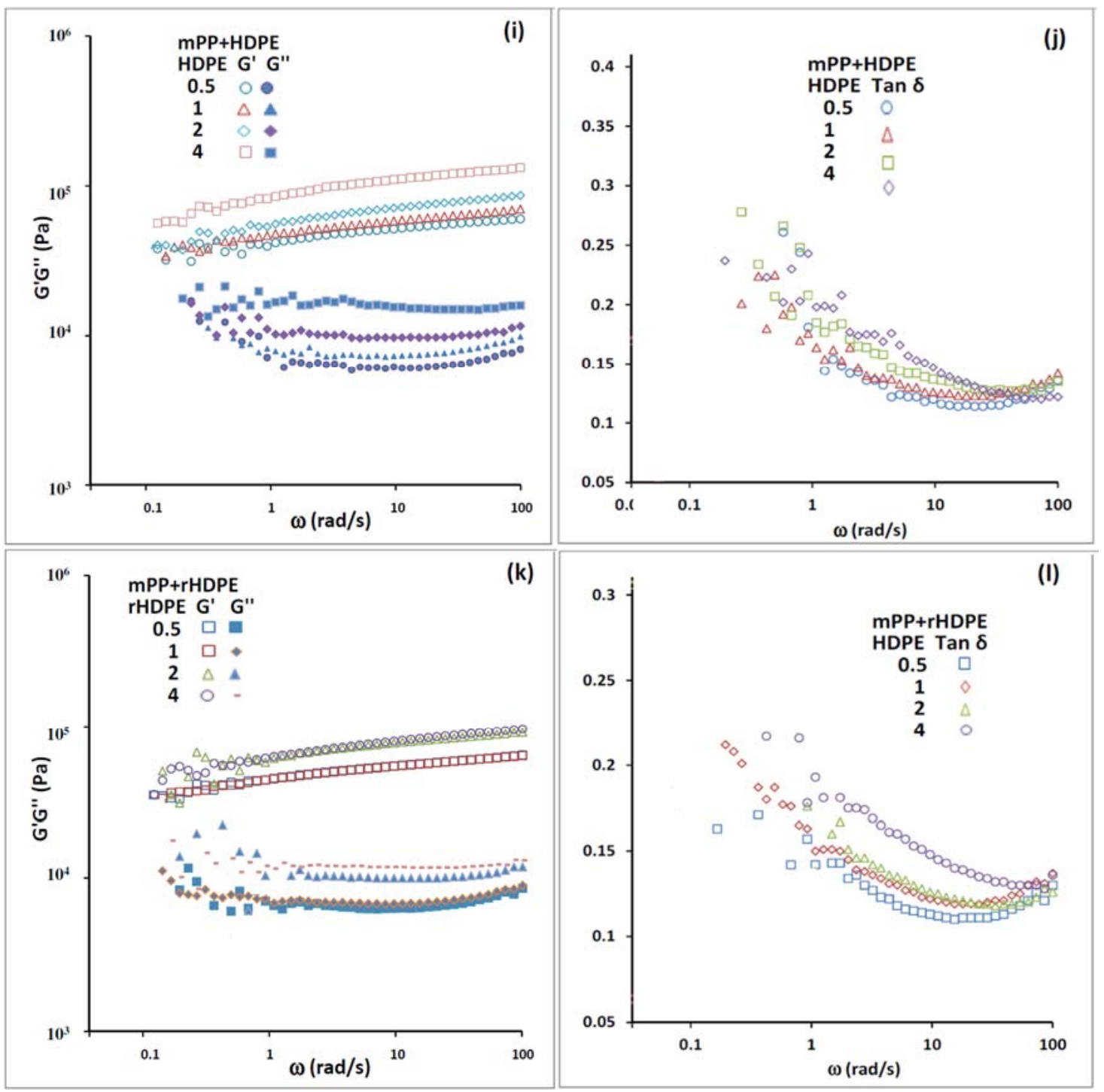

\section{Conclusions}

Oil bleed performance of pure PP and mPP grease and modified with virgin and recycled HDPE was studied. Based on experimental results obtained it can be concluded that

- $\quad$ Both PP and mPP exhibit similar oil bleed tendencies. However, mPP shows a slightly higher thickening tendency with the same thickener concentration over PP.

- HDPE increased $\mathrm{G}^{\prime}$ and $\mathrm{G}^{\prime \prime}$ values of PP and mPP greases thereby inhibiting oil bleed tendency.

- The oil bleed inhibiting tendency of these modified greases is sensitive to temperature, HDPE content and overall thickener content.

- The oil bleed tendency of greases varies from thickener to thickener but grease with same thickener type tends to bleed more oil which has comparatively higher viscous response (high $\left.\mathrm{G}^{\prime \prime}\right)$ than elastic (low $\left.\mathrm{G}^{\prime}\right)$.

In future work, exhaustive microscopy analysis will be done to look into the microstructure of polymers and correlation with oil bleed tendency. 


\section{Acknowledgments}

Authors are thankful to the management of IOCL, R\&D Centre, Faridabad, India for providing opportunity to carryout research work and granting permission to submit paper for publication in the journal "Lubricants".

\section{Author Contributions}

The contribution of the first author Ravi Dixena includes design of experiments, performing experiments, interpretation of the collected data, and writing the manuscript. The contribution of supervisors Elteu Sayanna and Rajendra Badoni includes the design and plan of experiments, interpretation of the collected data, and revision of the manuscript.

\section{Conflicts of Interest}

The authors declare no conflict of interest.

\section{References}

1. Rizvi, S.Q.A. Lubricant Chemistry, Technology, Selection, and Design; ASTM International: West Conshohocken, PA, USA, 2009; p. 443.

2. NLGI. Lubricating Grease Guide; National Lubricating Grease Institute: Kansas City, MO, USA, 1987.

3. Delgado, M.A.; Valencia, C.; Sanchez, M.C.; Franco, J.M.; Gallegos, C. Influence of soap concentration and oil viscosity on the rheology and microstructure of lubricating greases. Ind. Eng. Chem. Res. 2006, 45, 1902-1910.

4. Couronne, I.; Vergne, P.; Mazuyer, D.; Troung-Dinh, N.; Girodin, D. Effects of grease composition and microstructure on film thickness in rolling contact. Tribol. Trans. 2003, 46, 31-36.

5. Baart, P.; Vorst, B.V.D.; Lugt, P.M.; Ostayen, R.A.J.V. Oil-bleed model for lubricating grease based on viscous flow through a porous microstructure. Tribol. Trans. 2010, 53, 340-348.

6. Mittinen, J.; Andersson, P.; Wikstro, V. Analysis of grease lubrication of a ball bearing using acoustic emission measurement. J. Eng. Tribol. 2001, 215, 535-544.

7. Yuka, C.; Kogyo, K.K. Non-Diffusive Grease. JP Patent 63057693A, 1988.

8. Takahashi, O.; Kume, M. A study on non-oil diffusive greases. NLGI Spokesm. 1999, 57, 25-30.

9. John, A.; Waynick, B. Polyurea Grease with Reduced Oil Separation. U.S. Patent 4759859, 1988.

10. Meijer, D. Polymer Thickened Lubricating Grease. Eur. Patent 0700986B1, 1995.

11. Meijer, D.; Lankamp, H. Polymer Thickened Lubricants for High Temperatures. U.S. Patent $5846918,1998$.

12. Martin-Alfonso, J.E.; Valencia, C.; Sanchez, M.C.; Franco, J.M.; Gallegos, C. Development of new grease formulations using recycled LDPE as rheology modifier additive. Eur. Polym. J. 2007, 43, 139-149.

13. Martin-Alfonso, J.E.; Valencia, C.; Sanchez, M.C.; Franco, J.M.; Gallegos, C. Evaluation of different polyolefins as rheology modifier additives in lubricating grease formulations. Mater. Chem. Phys. 2011, 128, 530-538. 
14. Polyshuk, T.A.; Johnson, H.L. Grease Composition Containing Atactic Polypropylene. U.S. Patent 3290244, 1966.

15. Martin-Alfonso, J.E.; Romero, A.; Valencia, C.; Franco, J.M. Formulation and processing of virgin and recycled polypolefin/oil blends for the development of lubricating greases. J. Ind. Eng. Chem. 2013, 19, 580-588.

16. Bill, M. Grease. U.S. Patent 3392119A, 1665.

17. Yao, C. Maleated Polypropylene Blend for Melt-Bonding Applications. Eur. Patent 0408470 A1, 1991.

18. Mishra, M.K.; Rubbin, I.D. Functionalized Graft Co-Polymer as a Viscosity Index Improver, Dispersant, and Antioxidant Additive and Lubricating Oil Composition Containing Same. U.S. Patent 5409623, 1995.

19. Keener, T.J.; Stuart, R.K.; Brown, T.K. Maleated coupling agents for natural fibre composites. Appl. Sci. Manuf. 2004, 35, 357-362.

20. Cann, P.M. Starved grease lubrication of rolling contacts. Tribol. Trans. 2008, 42, 867-873.

21. Martin-Alfonso, J.E.; Valencia, C.; Sanchez, M.C.; Franco, J.M.; Gallegos, C. Rheological modification of lubricating grease with recycled polymers from different plastic waste. Ind. Eng. Chem. Res. 2009, 48, 4136-4144.

22. Meijer, D. Polymer Thickened Lubricating Grease. Eur. Patent 0700986 B1, 1995.

23. Martin-Alfonso, J.E.; Valencia, C.; Franco, J.M. Effect of amorphous/recycled polypropylene ratio on thermo-mechanical properties of blends for lubricating applications. Polym. Test. 2013, 32, 516-524.

24. Martin-Alfonso, J.E.; Moreno, G.; Valencia, C.; Sanchez, M.C.; Franco, J.M.; Gallegos, C. Influence of soap/polymer concentration ratio on the rheological properties of lithium lubricating greases modified with virgin LDPE. J. Ind. Eng. Chem. 2009, 15, 687-693.

(C) 2014 by the authors; licensee MDPI, Basel, Switzerland. This article is an open access article distributed under the terms and conditions of the Creative Commons Attribution license (http://creativecommons.org/licenses/by/4.0/). 